Quim. Nova, Vol. 36, No. 4, 502-506, 2013

\title{
CHEMICAL CHARACTERIZATION BY GC-MS AND PHYTOTOXIC POTENTIAL OF NON-POLAR AND POLAR FRACTIONS OF SEEDS OF Dioteryx odorata (Aubl.) Willd. FROM VENEZUELAN REGIONS
}

\author{
Alberto de J. Oliveros-Bastidas* \\ Departamento de Química, Facultad de Ciencias, Universidad de Los Andes, Núcleo Universitario Pedro Rincón Gutiérrez, La \\ Hechicera, Mérida 5101, Estado Mérida, Venezuela \\ Antonio J. Demuner \\ Departamento de Química, Universidade Federal de Viçosa, Av. P. H Rolf, s/n, 36570-000 Viçosa - MG, Brasil \\ Luiz Claudio de Almeida Barbosa \\ Departamento de Química, Universidade Federal of Minas Gerais, Av. Pres. Antônio Carlos, 6627, Campus Pampulha, $31270-901$ \\ Belo Horizonte - MG, Brasil. \\ Recebido em 22/5/12; aceito em 24/10/12; publicado na web em 12/3/13

\begin{abstract}
Dipteryx odorata (Aubl.) Willd. is a tall arboreal species native to Central and Northern South America. This paper describes the chemical characterization and phytotoxic potential of polar and non-polar extracts from D. odorata seeds. Structural determinations were accomplished by chemical derivatization and analyzed by GC/MS. The chemical composition of the non-polar fraction (hexane and dichloromethane) presented fatty acids as major constituent. Medium polar and polar fractions (ethyl acetate and ethanol: water) contained carboxylic acid and high 6,7-Dyhidroxycoumarin- $\beta$-D-glucopyranoside content, not previously reported for seeds of $D$. odorata. Extracts showed a significant level of phytotoxic activity, correlated to the content of coumarin derivatives, predominantly in the polar fraction.
\end{abstract}

Keywords: Dipteryx odorata; 6,7-Dyhidroxycoumarin- $\beta$-D-glucopyranoside; phytotoxic activity.

\section{INTRODUCTION}

Dipteryx odorata (Aubl.) Willd. is a tall arboreal species native to Central and Northern South America, Bolivia, Brazil, French Guiana, Venezuela, Peru, Colombia, Benin, Nigeria, Ivory Coast, and Guyana. ${ }^{1,2}$ It is commonly known as the "Tonka bean" tree. Other popular names used to refer to the tree include Cumaru-amarelo, baru, camaru-ferro, cambaru, cambaru-ferro, catinga-deboi, champagne, champanha and cumaru, among others. The seeds of $D$. odorata, known locally as "fava de morcego" are consumed as snacks in dried and salted form by the local population. To use this hard fruit, it must first be opened and the seeds extracted. These seeds are then dried and stored in barrels for $24 \mathrm{~h} .{ }^{3}$ During this period, the seeds undergo a process of fermentation. This process is evident from the resulting black color of the seeds. Due to their high content of coumarin and other flavorings, such as flavonoids, the plant's seeds have been put to many uses in the perfume and snuff industries for instance, and also in medical applications. Various conditions are treated with aqueous extracts, infusions or alcoholic extracts from the seeds. The seeds are characterized by having anti diuretic, hypoglycemic, anti-inflammatory and antispasmodic actions. Recently, the seeds were also found to have anti-carcinogenic effects, especially against breast cancer. ${ }^{4,5}$ Current literature carries general phytochemical information about the seeds. A review of literature yielded specific references to species found in Brazil but no phytochemical information about $D$. odorata species from Venezuelan regions was available. Preliminary analyses of the seeds indicate they are rich in oil that can serve as a source of essential fatty acids and fat-soluble vitamins; they can also be used as an ingredient in food and in pharmaceutical formulations, as well as a shortening agent in culinary practices. Previous phytochemical investigations on this plant have resulted in the isolation of coumarins, ${ }^{6,7}$ cassane diterpenoids,${ }^{8}$ isoflavonoids, ${ }^{9,10}$ fatty acids and lupane triterpenoids. ${ }^{11}$

*e-mail: aloliver@ula.ve
There is a commercial market for the use of extracts of Tonka beans in flavoring snuff, cigarettes, cigars, cocoa, and confectionery, and as an ingredient of perfumes, liqueurs, sachet powders, and cosmetics. ${ }^{1,7}$

Use of residual waste from the initial processing of the seeds of D. odorata for artisanal goods and industrial production employing traditional agricultural techniques, such as crop cover, may also be important. However, the phytotoxic evaluation of D. odorata waste has not yet been carried out. The aim of the present investigation was to partially evaluate the phytochemistry of $D$. odorata from Venezuela. For this characterization, an analysis of polar and non-polar fractions obtained from $D$. odorata seeds was carried out by GC-MS. Efforts were made to determine the phytotoxic activity of the major constituents of the extracts from the seeds. The information obtained can determine whether or not application of these seeds for weed control to reduce the use of synthetic herbicides is feasible, as well as their possible exploitation as a source of fatty acids of interest in the cosmetology and food industries.

\section{EXPERIMENTAL}

\section{GC-MS analysis}

GC-MS analyses were performed on a GC-MS apparatus (Shimadzu, model PQ5050) equipped with a Shimadzu AOC-5000 on-column auto injector and a fused silica capillary column (DB-5, $30 \mathrm{~m} \times 0.25 \mathrm{~mm}$ ID, $0.25 \mu \mathrm{m}$ film thickness). Operating conditions were as follows: helium as the carrier gas with a flow rate of $1.6 \mathrm{~mL} / \mathrm{min}$; column temperature $80^{\circ} \mathrm{C}$ for $5 \mathrm{~min}$, then increasing at $24.4{ }^{\circ} \mathrm{C} / \mathrm{min}$ from 80 to $285^{\circ} \mathrm{C}$; injector temperature, $290{ }^{\circ} \mathrm{C}$; volume injected, $1 \mu \mathrm{L}$; split ratio, 1.0. MS were recorded in electron ionization (EI) mode, with energy of $70 \mathrm{eV}$. The ion source temperature was $200{ }^{\circ} \mathrm{C} ; 5.00 \mathrm{~min}$ solvent cut time. The compounds were identified by comparison with the data held in the Wiley 7.0 and NIST libraries. 


\section{Repeatability of GC-MS equipment}

To assess the repeatability of the analytical instrument (GCMS), we prepared extract with 2 different concentrations in order to produce stable derivatives by derivatization methods, and analyzed the same sample 3 times in sequence. Repeatability was assessed by determining the relative standard deviation (RSD) of the GC-peak area, using Equation 1 below:

$$
\mathrm{RSD}=\mathrm{SD} / \text { mean } X 100
$$

\section{Transesterification of fixed oil (non-polar fraction)}

Triacylglycerols were transesterified, following the IUPAC method ${ }^{12}$ with some modifications, using the following procedure: approximately $100 \mathrm{mg}$ of oil, $2 \mathrm{~mL}$ of hexane and $0.2 \mathrm{~mL}$ of methanolic $2 \mathrm{M}$ solution of $\mathrm{KOH}$ were added to the test tube. The test tube was shaken for $5 \mathrm{~min}$ with Maelstrom stirrers and $2 \mathrm{~mL}$ of saturated sodium chloride was added, until the organic phase separated. Fatty acid methyl esters were analyzed in triplicate, after injection of a $1 \mu \mathrm{L}$ of the organic phase into a gas chromatograph coupled to a mass spectrometer.

\section{Derivatization with silylation (polar fraction)}

Silylation of organic compounds is the classical and most widely used derivatization procedure for metabolome analysis by GC-MS, thus it was the procedure used in this work. For the derivatization, a 3 mg extract sample is diluted with $60 \mu \mathrm{L}$ of dry pyridine and $100 \mu \mathrm{L}$ of bis(trimethylsilyl)trifluoroacetamide in $1 \%$ of trimethylchlorosilane (BSTFA-Fluka ChemikA). The mixture is heated at $70^{\circ} \mathrm{C}$ for $30 \mathrm{~min}$. A $1 \mu \mathrm{L}$ aliquot of the resulting solution is used for analysis by GC-MS.

\section{Phytotoxic activity}

Bioassays were performed using Petri dishes (90 mm diameter) with one sheet of Whatman No.1 filter paper as support. Germination and growth were conducted in aqueous solutions at controlled $\mathrm{pH}$ by using $10^{-2} \mathrm{M}$ of 2-[N-morpholino]ethanesulfonic acid (MES) and 1 $\mathrm{M}$ of $\mathrm{NaOH}(\mathrm{pH}=6.0)$. Compounds and extract to be assayed were dissolved in DMSO, and these solutions were diluted with buffer (5 $\mu \mathrm{L}$ of DMSO solution/mL buffer) so that test concentrations for each compound $\left(10^{-3}, 5 \times 10^{-4}, 10^{-4}, 5 \times 10^{-5}\right.$, and $\left.10^{-5} \mathrm{M}\right)$ were reached. This procedure facilitated the solubility of the assayed compounds.

\section{Target species}

Cucumis sativus (Cucurbitaceae, Ferry-Morse poinsett 76) seeds were used as received. The number of seeds placed in each Petri dish was 10 , and $5 \mathrm{~mL}$ of treatment, control, or internal reference (herbicide) solution were added to each Petri dish. Four replicates (40 seeds) were used. After adding seeds and aqueous solutions, the Petri dishes were sealed with Parafilm to ensure closed-system models. Seeds were further incubated in 25 controlled environment growth chambers, in the absence of light. The bioassays took 6 days. After growth, the plants were frozen at $-10^{\circ} \mathrm{C}$ for $24 \mathrm{~h}$ to avoid subsequent growth during the measurement process. This facilitated the handling of the plants and allowed a more accurate measurement of root and shoot lengths. The commercial herbicide Glifosan $\left[747^{\circ}\right.$ $\mathrm{N}$-(phosphonomethyl)glysine ] was used as the internal reference, according to a comparative study previously reported. ${ }^{13}$ The herbicide was used at the same concentrations and under the same conditions as the extract under study. Buffered aqueous solutions with DMSO and without tested compound were used as control samples.

\section{Plant material}

The fruit of Dipteryx odorata (Aubl.) Willd. was taken as a sample. Exactly 300 fruits were obtained from public markets located in regions of the Venezuelan plains. Seeds $(\mathrm{g} \times$ seed $=1.53 \pm 0.09, \mathrm{n}=$ 300) were extracted from ripe fruits. These were dried at room temperature, and protected from moisture. The seeds were then dried at a temperature of $40{ }^{\circ} \mathrm{C}$ to constant weight (for 4 days), pulverized and sieved, using only particles measuring less than $0.6 \mathrm{~mm}$ for extraction.

\section{Extraction and chromatographic separation}

\section{Extraction}

The dried seed powder ( $30 \mathrm{~g})$ was extracted sequentially by maceration assisted with ultrasonic baths (Bronson 5510) x3, using hexane (Hx), dichloromethane (DCM), ethyl acetate (EtOAc), and ethanol:water (EtOH: $\left.\mathrm{H}_{2} \mathrm{O} ; 1: 1\right)$. The extraction procedure was optimi$\mathrm{zed}^{14} \mathrm{using}$ a ratio of $0.1 \mathrm{~g} \mathrm{x} \mathrm{mL}$ of extraction solvent. The extraction time was $120 \mathrm{~min}$. Under these conditions, the \% yield obtained was $27.4 \pm 3.4 ; 1.7 \pm 4 ; 0.3 \pm 0.1$; and $3.3 \pm 0.3(X \pm R S D, n=3)$, for $\mathrm{Hx}$, DCM, EtOAc and EtOH: $\mathrm{H}_{2} \mathrm{O}$, respectively. Between extractions, the residual solid was taken to dryness at room temperature, before extraction using the solvent. In each case, the solvent was evaporated under reduced pressure $\left(40^{\circ} \mathrm{C} ; 400 \mathrm{~mm} \mathrm{Hg}\right)$. In this study, fractions were analyzed by GC-MS in order to identify polar and non-polar metabolites and evaluate their phytotoxic activity.

\section{Statistical analysis}

Data were statistically analyzed using Welch's test, with significance set at 0.01 and 0.05 . Results are expressed as percentage differences to control. Zero represents control, positive values represent stimulation of the studied parameter, and negative values represent inhibition. ${ }^{13}$ Once the germination and growth data was acquired, cluster analysis was used to group compounds with similar phytotoxicity behaviors and associate them with their molecular structure. Complete Linkage was used as an amalgamation rule and the distance measurement was based on Squared Euclidean Distances, given by Equation 2 below:

$$
d(x, y)=\sum_{i}\left(x_{i}-y_{i}\right)^{2}
$$

where d $(x, y)$ is the Squared Euclidean Distance (i-dimensional), i represents the number of variables, and $\mathrm{x}$ and $\mathrm{y}$ the observed values.

The cluster was obtained using Statistica ${ }^{\circledR}$ v. 5.0 software and was done on the basis of growth parameters. $\mathrm{EC}_{50}$ values were obtained after adjusting phytotoxicity data to concentration (logarithmic scale), to a sigmoidal dose-response curve, defined by Equation 3 below:

$$
Y=Y_{\min }+\frac{Y_{\max }-Y_{\min }}{1+10^{\log E C 50-X}}
$$

where $\mathrm{X}$ indicates the logarithm of the concentration, $\mathrm{Y}$ indicates the response (phytotoxicity) and $\mathrm{Y}_{\max }$ and $\mathrm{Y}_{\min }$ are the maximum and minimum values of the response, respectively. Goodness of fit is described by the determination coefficient $\left(r^{2}\right)$. The adjustment and $r^{2}$ were obtained using Graph Pad Prism ${ }^{\circledR}$ software v. 4.00.

\section{RESULTS AND DISCUSSION}

Seeds of $D$. odorata showed high fatty acid content (i.e. hexane fraction) with a mean of $27.4 \%$ dry weight. The literature reveals 
scant information concerning the content and fatty acid composition in the genus Dipteryx, and only partial characterization records are available for D. odorata. ${ }^{11}$ For D. lacunifera and D. alata, fatty acid content of between 39 and $45 \%$ were reported. ${ }^{15,16}$

\section{GC- analysis}

\section{Fatty acid composition}

The product obtained by triglyceride transesterification shows the seed oil presented in the GC-MS analysis as a total ion chromatogram with 12 peaks, whose comparison with the spectra corresponding to the library device is shown in Table 1.

Table 1. Fatty acid composition of fractions Hx, DCM and EtOAc from $D$. odorata seeds

\begin{tabular}{lccc}
\hline & $\operatorname{Tr}(\mathrm{min})$ & \% Rel. (RSD) & Similarity $(\%)$ \\
\hline Fraction Hx & & & \\
Hexadecanoic acid (C16:0) & 36.700 & $10.69(5.14)$ & 95 \\
Docosanoic acid (C23:0) & 39.350 & $0.07(7.14)$ & 90 \\
9-Octadecenoic acid (C18:1) & 41.133 & $0.86(2.31)$ & 92 \\
Octadecanoic acid (C18:0) & 41.725 & $43.81(3.01)$ & 94 \\
Octadecenoic acid (C18:1) & 41.500 & $5.62(2.01)$ & 91 \\
Eicosanoic acid (C20:0) & 46.042 & $3.74(1.93)$ & 94 \\
13-Docosenoic acid (C22:0) & 49.650 & $1.97(1.51)$ & 93 \\
Tetracosanoic acid (C24:0) & 53.950 & $11.32(2.22)$ & 91 \\
Heptacosanoic acid (C27:0) & 55.858 & $16.14(2.12)$ & 88 \\
Triacontenoic acid (C30:0) & 50.258 & $1.26(3.83)$ & 91 \\
\hline Fraction DCM & & & \\
Hexadecanoic acid (C16:0) & 35.887 & $18.35(4.21)$ & 95 \\
Heptadecanoic acid (C17:0) & 40.050 & $53.65(1.21)$ & 90 \\
Octadecanoic acid (18:0) & 40.892 & $9.83(4.13)$ & 92 \\
Benzenebutanoic acid & 41.008 & $9.80(3.11)$ & 86 \\
n-nonadecanol-1 & 45.042 & $6.16(3.22)$ & 86 \\
Docosanoic acid (C22:0) & 48.942 & $2.21(3.31)$ & 90 \\
\hline Fraction EtOAc & & & \\
Benzeneacetic acid & 33.000 & 15.47 & 78 \\
Hexadecenoic acid & 35.567 & 19.27 & 87 \\
Oleic acid & 39.975 & 11.43 & 92 \\
Octadecanoic acid & 40.500 & 8.78 & 90 \\
Phenol,2,4'-isopropylidene & 40.825 & 30.81 & 81 \\
1,2-benzenodicarboxilic acid & 48.367 & 8.40 & 85 \\
Nonadecanoic acid & 48.900 & 5.84 & 91 \\
\hline
\end{tabular}

*Fatty acid detected as methyl ester. The results show the average value and standard deviation of the analysis of three samples.

$81.96 \%$ of methyl esters were identified as being derived from 4 fatty acids (hexanoic, tricosanoic, heptacosanoic, and tetracosanoic acids). Fatty acids from 16 to 30 carbon atoms containing one double bond were detected. Saturated fatty acids with C23:0 were present in trace quantities.

Saturated fatty acids were the most abundant types, with C18:0 being predominant in the Hx fraction (43.81\%); and C17:0 in the DMC fraction (53.65\%). Other saturated fatty acids such as C16:0 (10.69\%), C20:0 (3.74\%) and C24:0 (11.32\%) were also identified. Vieira Junior ${ }^{15}$ reported saturated fatty acid content in D. lacunifera of $22.40 \%$, constituted by $14.34 \% \mathrm{C} 16: 0,4.55 \% \mathrm{C} 18: 0$ and $3.51 \%$ C24:0. Unsaturated fatty acids represented $77.58 \%$, of the total fatty acids content. In this research, $D$. odorata showed a high fatty acids content (27.4\%), taking into account only the hexane fraction, represented by $10 \% \mathrm{C} 16: 0,43.81 \% \mathrm{C} 18: 0$, and $5.62 \%$ for $\mathrm{C} 18: 1$. Thus,
C18:0 had the greatest contribution in total fatty acids content, being significantly greater than in D. lacunifera.

This fatty acid has intensive use in the cosmetics industry, and in soap and candle manufacturing. ${ }^{17}$ Thus, seeds of $D$. odorata may become an attractive raw material for exploitation. The $\mathrm{C} 16: 0$ content increases to $18.35 \%$, if the DCM fraction is considered. Interestingly, the fraction obtained with EtOAc, showed $53.65 \%$ of C17:0 heptadecanoic acid.

These substances play an important role in the mediation of immunologic, allergic and inflammatory reactions and in the control of hemostasy. ${ }^{18,19}$ This fatty acid has been reported as an anti-nutritional factor, ${ }^{20}$ as it inhibits the action of digestive enzymes in the digestive tracts of humans and other living organisms. These results therefore show the potential toxicity of the extracts prepared from seeds of D. odorata in traditional medicine.

Although the majority of the fatty acids found in the plant have an even number of carbon atoms (usually 14 to 24), these are minor species. However, the results showed high content of odd-numbered carbon chain acids, mainly heptanoic acid representing $53.65 \%$ of the DCM fraction. This renders D. odorata an abundant natural source of heptanoic acid, a property previously unknown for this plant species.

\section{Derivatization with silylation}

The product obtained by silylation of the polar fraction of seeds presented in the GC-MS analysis showed 14 peaks. In general, this fraction contains carboxylic acid derivatives and monomeric sugar. However 6,7-Dihydroxycoumarin- $\beta$-D-Glucopyranoside (Esculin) represents $50 \%$ of this fraction (Table 2). This is the first report on the presence of Esculin in seeds of $D$. odorata. Thus, D. odorata studied in this work showed a high concentration of coumarin and esculin, used in the treatment of diseases in traditional medicine, in the polar fraction. A number of studies have demonstrated the importance of these natural products as chemopreventive agents. ${ }^{21,22}$

Table 2. Polar fraction composition of $D$. odorata seeds

\begin{tabular}{lccc}
\hline Fatty acid & $\operatorname{Tr}(\mathrm{min})$ & $\%$ Rel. (RSD) & Similarity $(\%)$ \\
\hline Butanodioic acid & 20.342 & $0.42(5.21)$ & 90 \\
Propanedioic acid & 22.267 & $0.20(6.11)$ & 83 \\
D-Glucuroic acid & 29.242 & $21.4(1.23)$ & 83 \\
Myo-Inositol & 30.033 & $0.25(4.23)$ & 85 \\
Glucofuranoside & 30.458 & $2.61(3.34)$ & 80 \\
Ribitol & 31.300 & $8.47(1.14)$ & 80 \\
Mannose & 32.067 & $3.39(3.45)$ & 90 \\
$\alpha$-D-Glucopyranoside & 33.308 & $0.44(5.12)$ & 90 \\
D-Arabonose & 34.500 & $0,48(4.34)$ & 90 \\
Scyllo-Inositol & 36.790 & $6.87(2.21)$ & 90 \\
6,7-Dihidroxycoumarin- $\beta-D-$ & 49.00 & $50(2.23)$ & 90 \\
Glucopyranoside & & & \\
Tallonic acid & 52.517 & $3.89(2.21)$ & 90 \\
D-Galactoside & 75.783 & $1.58(1.23)$ & 90 \\
\hline
\end{tabular}

The results show the average value and standard deviation of the analysis of three samples.

Coumarins comprise a group of natural compounds widely distributed in plants and have recently drawn great attention for their broad biological activities. ${ }^{23}$ Esculetin is known to be a lipoxygenase inhibitor and to inhibit the production of leukotrienes through the lipoxygenase pathway. ${ }^{24}$ Esculetin also scavenges hydroxyl radicals ${ }^{25}$ and inhibits lipid peroxidation in rat liver. ${ }^{26}$ Furthermore, it has been reported that esculetin inhibits mammary carcinogenesis. ${ }^{27,28}$

Another study showed that esculetin and esculin can protect biomolecules from oxidative damage generated in the initial process 
of carcinogenesis. ${ }^{29,30}$ Thus, the mass fraction of seeds of $D$. odorata is a rich source of coumarin and esculin, showing high levels of concentration of these compounds. These compounds are consumed in the preparations of $D$. odorata, and although there is evidence of beneficial effects against cancer, they remain a potential source of harmful xenobiotics to humans.

\section{General bioactivity profiles}

Figure 1 shows the phytotoxic activity in shoots of different extract of seeds of $D$. odorata, as well as the internal reference of herbicide and coumarin, which has been included in the bioassays since it represents one of the major constituents in extracts of $D$. odorata. ${ }^{12}$ All active extracts showed inhibitory profiles. According to the activity, phytotoxic compounds are extracted mainly in more polar fractions (EtOAc and EtOH: $\mathrm{H}_{2} \mathrm{O}$ ). In general terms, the assayed compounds exerted significant effects at $250 \mathrm{ppm}$. The extract showing most intense effects at lower dilutions was EtOH: $\mathrm{H}_{2} \mathrm{O}$ (Table 3, $\mathrm{EC}_{50}=8.28, r^{2}=0.98$, root length). All extracts showed substantial phytotoxic activity, mainly in root growth and shoots.
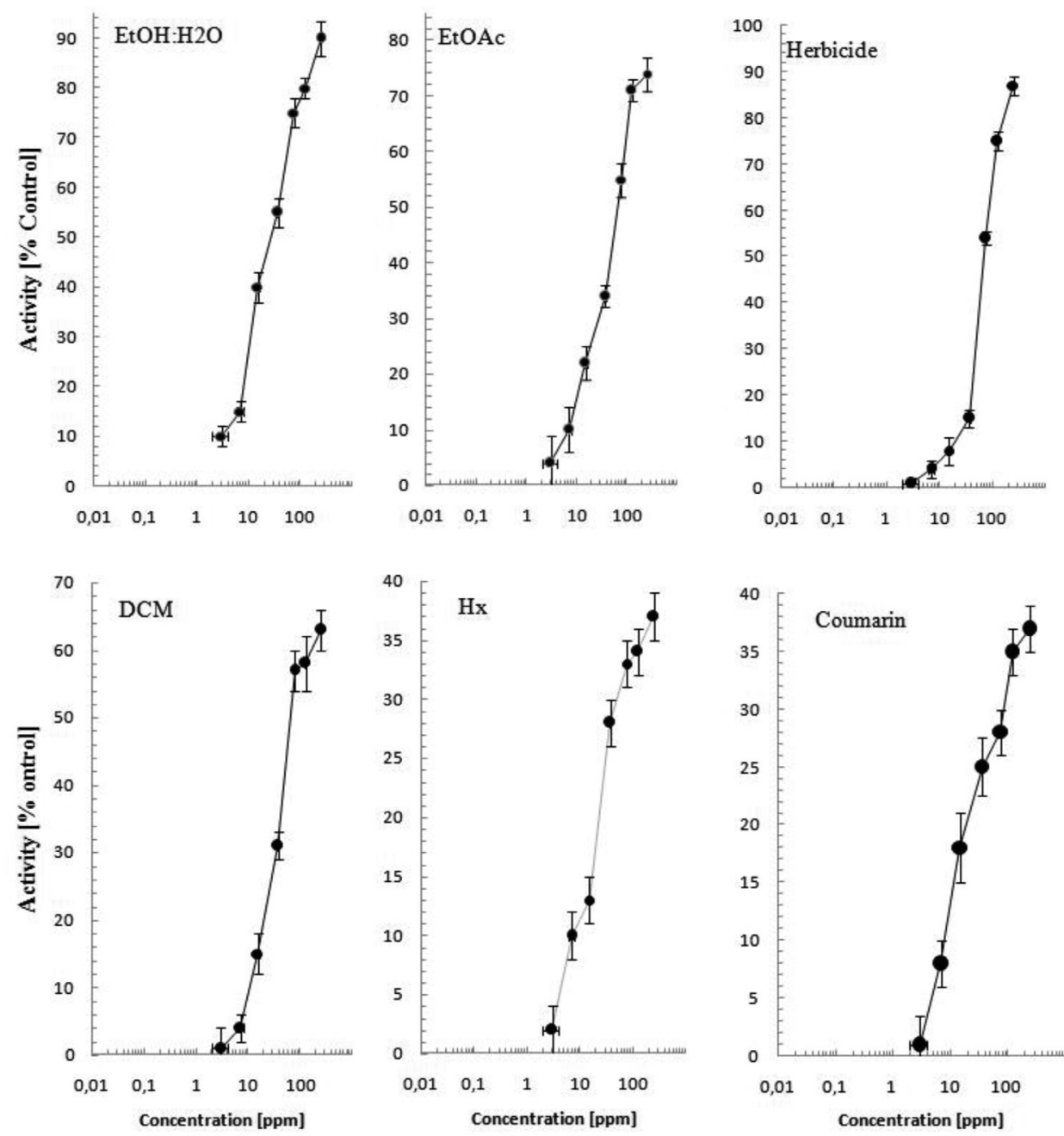

Figure 1. Activity phytotoxic of extract obtained from seeds of D. odorata on grown of C. sativum

Table 3. Dose-response calculation for determining the $\mathrm{EC}_{50}$ of different extracts of $D$. odorata on the growth and germination of $C$. sativum

\begin{tabular}{|c|c|c|c|c|c|c|}
\hline & $\mathrm{Hx}$ & DCM & EtOAc & EtOH: $\mathrm{H}_{2} \mathrm{O}$ & Herbicide & Coumarin \\
\hline \multicolumn{7}{|c|}{ Shoot } \\
\hline $\mathrm{EC}_{50}(\mathrm{ppm})$ & 17.79 & 36.88 & 52.16 & 25.26 & 68.55 & 4.571 \\
\hline $\mathrm{r}^{2}$ & 0.9834 & 0.9789 & 0.9877 & 0.9905 & 0,994 & 0.9899 \\
\hline Error & 2.18 & 4.76 & 3.87 & 3.80 & 2.620 & 1.920 \\
\hline \multicolumn{7}{|c|}{ Root } \\
\hline $\mathrm{EC}_{50}(\mathrm{ppm})$ & 241.17 & 13.25 & 165.8 & 8.28 & 15.24 & 201.4 \\
\hline$r^{2}$ & 0.9285 & 0.9919 & 0.9804 & 0.9812 & 0.9787 & 0.9767 \\
\hline Error & 6.97 & 2.66 & 1.12 & 4.70 & 4.05 & 4.30 \\
\hline \multicolumn{7}{|c|}{ Germination } \\
\hline $\mathrm{EC}_{50}(\mathrm{ppm})$ & 1134 & 132.53 & 167.9 & 18.92 & 64.19 & 11.54 \\
\hline$r^{2}$ & 0.9831 & 0.9810 & 0.9595 & 0.9865 & 0.9968 & 0.9787 \\
\hline Error & 1.414 & 1.646 & 2.880 & 3.472 & 1.197 & 1.397 \\
\hline
\end{tabular}


Cluster analysis performed on the basis of root, shoot length and germination is shown in Figure 2. According to their phytotoxicity profiles, the extract can be divided into two groups: G2, which includes the extracts with the highest phytotoxic effects (herbicide and $\mathrm{EtOH}: \mathrm{H}_{2} \mathrm{O}$ extract), and $\mathrm{G1}$, in which extracts with moderate or null effects are grouped. G1 is subdivided into two subgroups: G1A, formed by Hx extract and coumarin standard, and G1B, formed by DCM and EtOAc extracts. The EtOH: $\mathrm{H}_{2} \mathrm{O}$ extract shows activity compared to the agrochemical, and this probably contains the most active compounds or highest concentrations relative to the other fractions. As described below, this fraction consists mainly of 6,7-Dihidroxicoumarin- $\beta$-D-Glucopyranoside (50\%), which has been reported as a compound with appreciable phytotoxic activity. ${ }^{17}$ Results indicate that the allelopathic potential of plants could be related to their phenolic compounds. It is possible to conclude that the presence of some fatty acids can reduce growth of plants, and potentially these extracts may be used to eliminate weeds. Further investigation into the allelochemicals detected could result in the development of herbicides, such as structural derivatives of coumarin, with less adverse effects on the environment and ecosystem. Moreover, the use of extracts directly may result in reducing the growth of weeds.

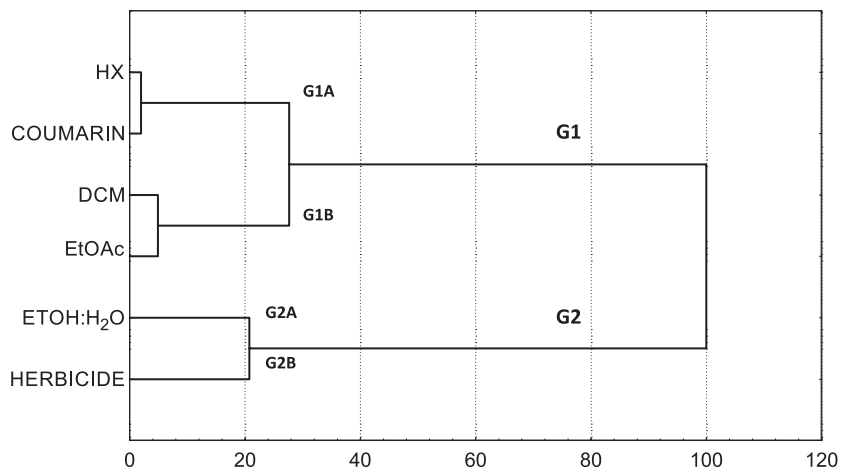

Figure 2. Cluster analysis for Cucumis sativus growth inhibition (effects on root, shoot length and germination)

In the case of $\mathrm{EtOH}: \mathrm{H}_{2} \mathrm{O}$, the $\mathrm{EC}_{50}$ values calculated were 25.26, 8.28 , and 18.92 for shoot length, root length and germination, respectively. In previous studies, coumarin content of around $2.5 \%$ by dry weight was reported. ${ }^{16}$ Since the activity exhibited by EtOH: $\mathrm{H}_{2} \mathrm{O}$ extract was comparable to that shown by coumarin, it is possible that coumarin in the extract is responsible for the activity observed.

\section{ACKNOWLEDGEMENTS}

Fellowships from the Universidad de Los Andes (U.L.A), Venezuela, and Fundação de Amparo à Pesquisa do Estado de Minas Gerais (FAPEMIG), Bolsa de Pesquisador Visitante- PV 2011, Brasil (A. O. B.).

\section{REFERENCES}

1. Allen, O. N.; Allen, E. K.; The Leguminosae, The University of Wisconsin Press: Madison, 1981.
2. Duke, J.; CRC Handbook of Medicinal Herbs, CRC Press: Boca Raton, 1985.

3. Ehlers, D.; Pfister, M.; Bork, W. R.; Toffel-Nadolny, P.; Z. Lebensm. Unter Forsch. 1995, 201, 278.

4. Egan, D.; O'Kennedy, R.; Moran, E.; Cox, D.; Thornes. R. D.; Drug Metab. Rev. 1990, 22, 503.

5. Lacy, A.; O'Kennedy, R.; Curr. Pharm. Des. 2004, 10, 3797.

6. Griffiths, L. A.; J. Exp. Bot. 1962, 26,169.

7. Sullivan, G.; J. Agric. Food Chem. 1982, 30, 609.

8. Godoy, R. L.; Lima, P. D.; Pinto, A. C.; de Aquino, F. R.; Phytochemistry 1989, 28, 642 .

9. Nakano, T.; Alonso, J.; Grillet, R.; Martin, A.; J. Chem. Soc., Perkin Trans. 1 1979, 9, 2107.

10. Socorro, M. P.; Pinto, A. C.; Kaiser, C. R.; Z. Naturforsch. 2003, 58b, 1206.

11. Nakano, T.; Suarez, M.; Planta Med. 1969, 18, 79.

12. Oliveros-Bastidas, A.; Cordero, I.; Paredes, D.; Buendía, D.; Macías, F.; Rev. Lat. Quim. 2011, 39,17.

13. Oliveros-Bastidas, A.; Rodríguez-Hernández, D.; Calcagno-Pissarelli, M.; Ciencia 2011, 19, 187.

14. IUPAC; Standard Methods for Analysis of Oils, Fats and Derivatives, Blackwell Scientific Publications: Oxford, $7^{\text {th }}$ ed., 1987.

15. Vieira, G. M.; Silva, H. R.; Bittencourt, T. C.; Chaves, M. H.; Simone, C. A.; Quim. Nova 2007, 30,1658.

16. Vallilo, M. I.; Tavares, M.; Aued, S.; Revista do Instituto Florestal 1990, vol. 2,115 .

17. Togashi, M.; Sgarbieri, V. C.; Ciência e Tecnologia de Alimentos 1994, 14,85 .

18. Einhelling, F. A. In Allelopathy: Organisms, Processes and Applications; Inderjit, D. K. M. M.; Einhelling, F. A., eds.; American Chemical Society: Washington, DC, 1995, vol. 582, p. 96.

19. Oyedeji, F. O.; Adeleke, B. B.; Akintola, C. B.; Trends Appl. Sci. Res. 2011, 6, 1 .

20. Calder, P. C.; Braz. J. Med. Biol. Res. 1993, 26, 901.

21. Voss, A.; Actualidades Dietéticas 1994, 1,1 .

22. Balogun, A. M.; Fetuga, B. L.; Food Chem. 1985, 17, 175.

23. Tsuda, H.; Ohshima, Y.; Nomoto, H.; Fujita, K.; Matsuda, E.; Iigo, M.; Takasuka, N.; Moore, M. A.; Drug Metab. Pharmacokinet. 2004, 19, 245.

24. Kanadaswami, C.; Lee, L. T.; Lee, P. P.; Hwang, J. J.; Ke, F. C.; Huang, Y. T.; Lee, M. T.; In Vivo 2005, 19, 895.

25. Egan, D.; O'Kennedy, R.; Moran, E.; Cox, D.; Prosser, E.; Thornes, R. D.; Drug Metab. Rev. 1990, 22, 503.

26. Neichi, T.; Koshihara, Y.; Murota, S.; Biochim. Biophys. Acta 1983, 753, 130.

27. Hiramoto, K.; Ojima, N.; Sako, K.; Kikugawa, K.; Biol. Pharm. Bull. 1996, 19, 558.

28. Martín-Aragón, S.; Benedí, J. M.; Villar, A. M.; Gerontology 1998, 44, 21.

29. Kitagawa, H.; Noguchi, M.; Oncology 1994, 51, 401.

30. Kaneko, T.; Tahara, S.; Takabayashi, F.; Harada, N.; Free Radical Res. 2004, 38, 839 .

31. Kaneko, T.; Tahara, S.; Takabayas, F.; Biol. Pharm. Bull. 2007, 30, 2052. 